\title{
Clustering Buku Perpustakaan Program Studi Diluar Domisili UNS Kabupaten Madiun Menggunakan Metode Fuzzy C-Means Clustering
}

Rifa Khoirunisa*, Kusrini, Emha Taufik Luthfi

Magister Teknik Informatika, Universitas Amikom Yogyakarta

*rifa.khoirunisa@students.amikom.ac.id

\section{Info Artikel}

Kata Kunci :

Clustering, Perpustakaan, Fuzzy C-

Means Clustering

Keywords :

Clustering, Library, Fuzzy C-Means

Clustering

Tanggal Artikel

Dikirim : 14 Januari 2020

Direvisi : 17 Januari 2020

Diterima : 30 Januari 2020

\section{Abstrak}

Perpustakaan merupakan salah satu sarana di dalam perguruan tinggi yang digunakan semua civitas akademika untuk mendapatkan pengetahuan, informasi. Di dalam perpustakaan perlu dilakukan penyimpanan dan pemeliharaan yang baik sehingga fungsi perpustakaan dapat dimaksimalkan. Dalam memelihara perpustakaan, diperlukan pembaruan buku yang dapat dilakukan setiap saat maupun secara berkala. Dalam pembaruan buku, tentunya diperlukan data-data pendukung seperti data buku yang banyak di pinjam maupun data buku yang tidak pernah dipinjam. Dalam perpustakaan PDD-UNS saat ini belum ada data yang menunjukkan banyaknya buku perpustakaan yang dipinjam, maka dari itu akan dilakukan penelitian yang akan mengelompokkan buku berdasarkan data peminjaman di perpustakaan dengan menggunakan metode Fuzzy C-Means Clustering. Jumlah cluster yang digunakan dalah penelitian ini berjumlah 3 dan berhenti pada iterasi ke3. Hasil dari FCM ini yaitu Cluster ke-1 yaitu jenis buku dengan kategori sistem, teknik komunikasi dan pertanian, kemudian cluster ke-2 yaitu pemrograman komputer dan ilmu teknik dan cluster ke-3 yaitu data dalam sistem komputer, komunikasi komputer, ensiklopedia, matematika dan teknologi kimia.

\section{Abstarct}

The library is one of the facilities for in higher education institutes which used all of its products to obtain knowledge of, information. In in a library needs to be done storage and maintenance of good manners and morals and so that function is the library can be maximized .Is to take care of the library, they are also required to the renewal of books that can be should be done every during and at regular intervals. In the renewal of a book, obviously this will only happen they are also required to data-data supporter as expectation for the books which data on the country young many get a loan is as well as data the book that was never borrow money that has been .In a library pdd-uns now there is no the data that indicates a considerable a borrowed book, that is why it is will be conducted the research which will mengcluster a book based on the data from the borrowing in a library with uses the method fuzzy cmeans clustering. The number of its cluster of used of them is an indonesian this research including an 3 and took his stand on iteration ke-3. The result of this is the fom cluster ke-1 is a book with category, system and agriculture, communication techniques then cluster ke-2 namely computer programming and engineering science and clusters of ke-3 namely data in computer systems, communication by computer, the encyclopedia, math and chemical technology. 


\section{PENDAHULUAN}

Perpustakaan menjadi sarana yang perlu ada didalam perguruan tinggi yang berfungsi sebagai tempat untuk menigkatkan pengetahuan, melakukan penyebaran informasi, di dalam perpustakaan terdapat berbagai macam buku yang dapat digunakan sebagai referensi untuk semua civitas akademika yang ada di perguruan tinggi[1]. Dalam menunjang pelaksanaan akademis perguruan tinggi diperlukan pemeliharaan terhadap perpustakaan. Dalam pemeliharaan tentu dibutuhkan pembaruang setiap saat maupun secara berkala. Salah satu cara yang digunakan untuk pembaruan yaitu penambahan bahan pustaka berupa buku[2]. Perpustakaan dijadikan sebagai unsur penunjang bagi mahasiswa untuk proses perkuliahan maupun sebagai sumber referensi bagi semua civitas akademika di perguruan tinggi, maka dari itu koleksi yang ada didalam perpustkaan harus dapat mendukung capaian tujuan pembelajaran program studi yang ada di dalam perguruan tinggi tersebut. Mutu dari perpustakaan terdapat pada buku yang tersedia di dalam perpustakaan tersebut[3]. Pengklasifikasian buku di perpustakaan berdasarkan dengan Dewey Decimal Classificatin (DDC) yang ditemukan oleh Melville Louis Kassuth Dewey (1851-1931). Buku yang berjudul "A Classification and subject index for a library" merupakan buku DDC edisi pertama yang diulis oleh Melville pada tahun 1876 [4]. Dalam pembaruan DDC terdapat penambahan subyek baru yang ditambahkan sesuai dengan perluasan dan perkembangan ilmu. Kelestarian DDC banyak digunakan di dunia dan dapat mencapai umur lebih dari satu abad, dikarenakan DDC ditinjau secara berkala dan selalu diterbitkan edisi yang terbaru. DDC menggunakan angka arab sebagai simbol notasi.

Penelitian yang dilakukan oleh Catur Sugeng Pribadi yang berjudul Pengambilan keputusan Pengadaan Buku Perpustakaan dengan Metode Fuzzy C-Means Clustering menghasilkan rekomendasi pegadaan buku perpustakaan yang didasarkan pada jumlah peminjaman per angkatan. Pada penelitian tersebut cluster yang digunakan berjumlah 4 cluster yang proses iterasinya berhenti pada iterasi ke 42 dengan maksimul iterasi 1000[4].

Penelitian yang dilakukan oleh Ahmad Dony Susetyo yang berjudul Sistem Rekomendasi Pengadaan Buku pada Badan Arsip dan Perpustakaan Daerah Provinsi Jawa Tengah dengan Metode Fuzzy C-Means Clustering menghasilkan sistem yang merekomendasikan pengadaan buku berdasarkan jumlah peminjaman yang ada. Cluster yang digunakan dalam penelitian ini berjumlah 2 dan maksimum iterasi 100.Proses FCM berhenti pada iterasi ke12 dengan pengelompokan 2 cluster 4 kategori jenis pekerjaan peminjam yaitu pekerjaan umum, swasta, pelajar dan PNS[5].

Permasalahan yang terjadi pada perpustakaan PDD-UNS saat ini adalah tidak adanya data yang menunjukkan buku apa yang banyak dipinjam berdasarkan kategori maupun berdasarkan judul buku. Jadi dalam pengadaan buku perpustakaan, transaksi peminjaman tidak dijadikan pertimbangan dalam pengadaan buku. Pengadaan buku perpustakaan hanya berdasarkan usulan dari prodi maupun dari pustakawan saja tanpa mempertimbangkan buku apa yang banyak diminati. Maka dari itu akan dilakukan penelitian untuk membantu petugas perpustakaan dalam menentukan buku yang akan di beli dengan menerapkan Fuzzy C-Means Clustering. Metode Fuzzy C-Means [7]-[15] adalah salah satu metode klasifikasi cluster yang memasukkan data kedalam cluster dengan menggunakan teori Fuzzy [4]. Fuzzy C-Means Custering merupakan algoritma clustering yang datanya dapat menjadi anggota dari suatu cluster dengan derajat yang didefinisikan dengan mengguanakan level anggota. Pada Fuzzy C-Means Clustering jumlah cluster yang akan dibentuk harus diketahui terlebih dahulu, pada penelitian ini cluster yang akan dibentuk berjumlah 3[6].

Berdasarkan penelitian di atas, dalam penelitian ini akan melakukan clustering pada buku perpustakaan berdasarkan jumlah peminjaman menggunakan Fuzzy C-Means Clustering. Penerapan Fuzzy C-Means Clustering dalam mencluster buku yang ada di perpustakaan berdasarkan jumlah peminjaman diharapkan dapat memberikan manfaat untuk petugas perpustakaan karena memperoleh informasi buku yang banyak dipinjam maupun yanh tidak pernah dipinjam sesuai dengan data yang akurat [2]. Maka dari itu akan dilakukan pemetaan yang dapat mengelompokkan buku yang sering dipinjam, jarang dipinjam dan tidak pernah di pinjam. Dari hasil penelitian ini akan memberikan data yang akurat mengenai buku yang banyak di pinjam sehingga pustakawan dapat menindaklajuti hal tersebut untuk dapat menggunakan data tersebut dalam pengadaan buku di perpustakaan.

\section{METODE PENELITIAN}

Dalam penelitian ini langkah yang dilakukan yaitu tahap pendahuluan, tahap mengumpulkan data dan mengolah data. Pada pendahuluan dimulai dengan menentukan latar belakang masalah, kemudian dilanjutkan dengan tahap pengumpulan data buku dan data peminjaman yang ada di perpustakaan PDD UNS dan juga. Kemudian dari data yang sudah didapatkan dilanjutkan tahap berikutnya yaitu tahap pengolahan data. Pada pengolahan data ini terdapat beberapa tahap diantaranya Menentukan jumlah cluster, nenentukan nilai matriks partisi awal, melakukan iterasi sampai dengan nilai iterasi dibawah 0,1. 
Pada Iterasi ini langkah yang dilakukan yaitu menghitung nilai centroid, melakukan perhitungan derajat keanggotaan, menghitung perubahan matriks partisi. Alur penelitian yang akan digunakan dalam penelitian ini tergambar pada gambar 1 .

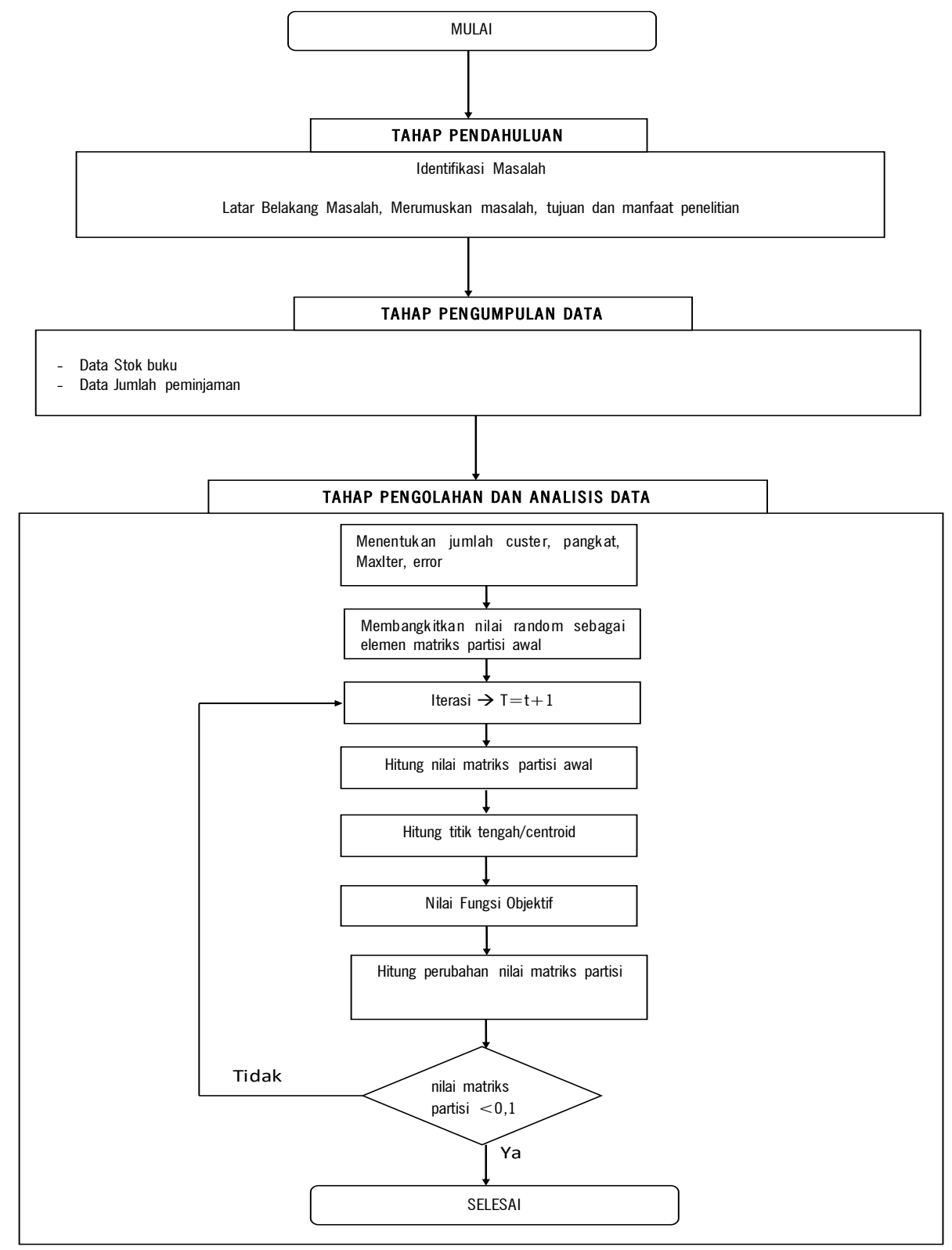

Gambar 1. Alur Penelitian

Penelitian yang akan dilaksanakan adalah penelitian eksperimen dengan menerapkan Fuzzy C-Means Clustering menggunakan pendekatan kuantitatif yang nantinya hasil dari penelitian ini merupakan informasi berupa hasil clustering buku perpustakaan di PDD-UNS. Algoritma dari Fuzzy C-Means yang akan dilakukan sebagai berikut:

Input data kedalam matriks berukuran $\mathrm{n} \times \mathrm{m}$ (dengan $\mathrm{n}=$ jumlah data sampel, $\mathrm{m}=$ atribut setiap data). Xij=data sample ke-i( $\mathrm{i}=1,2, \ldots, \mathrm{n})$, atribut ke-j(j=1,2,..,m).

a) Tentukan:

- Jumlah cluster (C)

- Pangkat (w)

- Maksimum iterasi (Maxlter)

- Error terkecil yang diharapkan $(\varepsilon)$

- Fungsi obyektif awal $(\mathrm{PO}=0)$

- Iterasi awal ( $\mathrm{t}=1)$ 
b) Membangkitkan nilai acak $\mu \mathrm{ik}, \mathrm{i}=1,2, \ldots, \mathrm{n} ; \mathrm{k}=1,2, \ldots, \mathrm{c}$; Menghitung jumlah setiap kolom (atribut)

$Q j=\sum_{k=1}^{c} \mu_{i k}$

Qj merupakan jumlah nilai dari derajat keanggotaan perkolom $=1$ dengan $\mathrm{j}=1,2, \ldots \mathrm{m}$

Hitung:

$\mu_{i k}=\frac{\mu_{i k}}{Q_{j}}$

c) Menghitung pusat Cluster / Nilai Centroid ke-k: Vkj, dengan $k=1,2, \ldots c$; dan j=1,2, ..m.

$$
V_{k j}=\frac{\sum_{i=1}^{n}\left(\left(\mu_{i k}\right)^{w} * X_{i j}\right)}{\sum_{i=1}^{n}\left(\mu_{i k}\right)^{w}}
$$

d) Menghitung fungsi obyektif pada iterasi ke-t, Pt.

$$
P_{t}=\sum_{i=1}^{n} \sum_{k=1}^{c}\left(\left[\sum_{i=1}^{m}\left(X_{i j}-V_{k j}\right)^{2}\right]\left(\mu_{i k}\right)^{2}\right)
$$

e) Menghitung hasil perubahan matriks partisi:

$$
\mu_{i k}=\frac{\left[\sum_{i=1}^{m}\left(X_{i j}-V_{k j}\right)^{2}\right]^{\frac{-1}{w-1}}}{\sum_{k=1}^{c}\left[\sum_{i=1}^{m}\left(X_{i j}-V_{k j}\right)^{2}\right]^{\frac{-1}{w-1}}}
$$

Dengan kondisi: i $=1,2, \ldots$; ;an $k=1,2, . . c$.

f) Pengecekan kondisi berhenti:

- Jika ( $|\mathrm{Pt}-\mathrm{Pt}-1| \leq \varepsilon)$ atau ( $\$ maxlter) maka berhenti;

- jika tidakt=t+1, ulangi langkah ke-4

\section{HASIL DAN PEMBAHASAN}

Pada penelitian ini akan dilakukan perhitungan dengan menggunakan Fuzzy C-Means Clustering untuk menentukan Cluster buku pada perpustakaan PDD-UNS. Data yang digunakan pada penelitian ini adalah data stok buku dan data peminjaman perpustakaan dari tahun 2013 sampai dengan 2017. Data buku yang dipinjam sudah dikelompokkan menurut kategory DDC, dan dari hal tersebut ada 10 kategory DDC yang digunakan dalam penelitian ini. Pada perhitungan Fuzzy CMeans Clustering akan ditentukan nilai awalnya yaitu :
a. Jumlah Cluster
$=3$
b. Pangkat
$=2$
c. Maksimum Iterasi
$=$ Maxlter
d. Error terkecil yang diharapkan $=€$
e. Fungsi Obyektif Awal $\quad=0$
f. Iterasi Awal
$=0$
$=1$

Kemudian membangkitkan nilai matriks partisi awal seperti yang ada pada tabel 1.

Tabel 1. Matriks Partisi Awal

\begin{tabular}{ccccc}
\hline \multicolumn{5}{c}{ Matriks Partisi Awal } \\
\hline No & $\boldsymbol{\mu}_{1}$ & $\boldsymbol{\mu}_{2}$ & $\boldsymbol{\mu}_{3}$ & Jumlah \\
\hline 1 & 0,6 & 0,3 & 0,1 & 1 \\
\hline 2 & 0,5 & 0,2 & 0,3 & 1 \\
\hline 3 & 0,8 & 0,1 & 0,1 & 1 \\
\hline 4 & 0,4 & 0,2 & 0,4 & 1 \\
\hline
\end{tabular}

88 | IJAI (Indonesian Journal of Applied Informatics) 


\begin{tabular}{ccccc}
\hline \multicolumn{6}{c}{ Matriks Partisi Awal } \\
\hline No & $\boldsymbol{\mu}_{1}$ & $\boldsymbol{\mu}_{2}$ & $\boldsymbol{\mu}_{3}$ & Jumlah \\
\hline 5 & 0,3 & 0,5 & 0,2 & 1 \\
\hline 6 & 0,7 & 0,1 & 0,2 & 1 \\
\hline 7 & 0,1 & 0,2 & 0,7 & 1 \\
\hline 8 & 0,2 & 0,6 & 0,2 & 1 \\
\hline 9 & 0,3 & 0,4 & 0,3 & 1 \\
\hline 10 & 0,5 & 0,1 & 0,4 & 1 \\
\hline
\end{tabular}

Dari nilai matriks partisi awal kemudian dilanjutkan dengan mencari nilai centroid atau pusat cluster yang terdapat dapat tabel 2.

Tabel 2. Nilai pusat Cluster

\begin{tabular}{ccc}
\hline Centroid & $\mathbf{V}_{\mathbf{1}}$ & $\mathbf{V}_{\mathbf{2}}$ \\
\hline 1 & 100,8445 & 118,2269 \\
\hline 2 & 88,9010 & 145,5446 \\
\hline 3 & 145,6814 & 142,9204 \\
\hline
\end{tabular}

Selanjutnya menghuitung nilai fungsi obyektif pada iterasi-1 dst. Pada iterasi- 1 nilai fungsi obyektif yang didapat adalah 31305,94 seperti pada tabel 3.

Tabel 3. Nilai Fungsi Obyektif

\begin{tabular}{|c|c|c|c|c|c|c|}
\hline \multirow{3}{*}{\multicolumn{3}{|c|}{$\begin{array}{l}\text { Perhitungan Fungsi Objektif } \\
\text { Kuadrat derajat keanggotaan data ke } \\
1\end{array}$}} & \multirow[b]{4}{*}{$\mathbf{P}_{1}$} & \multirow[b]{4}{*}{$\mathbf{P}_{2}$} & \multirow[b]{4}{*}{$\mathbf{P}_{3}$} & \\
\hline & & & & & & \multirow[b]{3}{*}{$\mathbf{P}_{1}$} \\
\hline & & & & & & \\
\hline$\mu_{1}{ }^{w}$ & $\mu_{2}{ }^{w}$ & $\mu_{3}{ }^{w}$ & & & & \\
\hline 0,36 & 0,09 & 0,01 & 2240,09 & 261,62 & 45,80 & 2547,50 \\
\hline 0,25 & 0,04 & 0,09 & 9105,70 & 1519,91 & 1775,61 & 12401,21 \\
\hline 0,64 & 0,01 & 0,01 & 123,02 & 19,03 & 30,93 & 172,98 \\
\hline 0,16 & 0,04 & 0,16 & 22,46 & 30,35 & 613,41 & 666,21 \\
\hline 0,09 & 0,25 & 0,04 & 579,62 & 1737,59 & 686,28 & 3003,49 \\
\hline 0,49 & 0,01 & 0,04 & 2450,70 & 66,28 & 593,43 & 3110,40 \\
\hline 0,01 & 0,04 & 0,49 & 145,59 & 570,81 & 2381,07 & 3097,46 \\
\hline 0,04 & 0,36 & 0,04 & 118,00 & 233,56 & 164,62 & 516,19 \\
\hline 0,09 & 0,16 & 0,09 & 67,33 & 71,61 & 114,69 & 253,63 \\
\hline 0,25 & 0,01 & 0,16 & 2215,52 & 128,65 & 3192,70 & 5536,87 \\
\hline \multicolumn{6}{|c|}{ Fungsi Objektif $P_{t}$} & 31305,94 \\
\hline
\end{tabular}

Setelah itu akan dihitung nilai perubahan matriks yang dapat digunakan untuk iterasi berikutnya. Pada tabel 4 merupakan hasil matriks partisi yang dilakukan pada iterasi ke-1.

Tabel 4. Perubahan Matriks Partisi

\begin{tabular}{ccccccc}
\hline $\mathbf{P}_{\mathbf{1}}$ & $\mathbf{P}_{\mathbf{2}}$ & $\mathbf{P}_{\mathbf{3}}$ & $\mathbf{P}_{\mathbf{1}}$ & $\boldsymbol{\mu}_{1}$ & $\boldsymbol{\mu}_{\mathbf{2}}$ & $\boldsymbol{\mu}_{\mathbf{3}}$ \\
\hline 6222,47 & 2906,84 & 4579,59 & 13708,90 & 0,45 & 0,21 & 0,33 \\
\hline 36422,78 & 37997,65 & 19729,02 & 94149,45 & 0,39 & 0,40 & 0,21 \\
\hline 192,22 & 1903,04 & 3092,93 & 5188,19 & 0,04 & 0,37 & 0,60 \\
\hline 140,34 & 758,71 & 3833,81 & 4732,86 & 0,03 & 0,16 & 0,81 \\
\hline 6440,24 & 6950,36 & 17156,89 & 30547,49 & 0,21 & 0,23 & 0,56 \\
\hline 5001,43 & 6627,88 & 14835,65 & 26464,96 & 0,19 & 0,25 & 0,56 \\
\hline 14558,53 & 14270,21 & 4859,32 & 33688,06 & 0,43 & 0,42 & 0,14 \\
\hline 2949,98 & 648,79 & 4115,61 & 7714,39 & 0,38 & 0,08 & 0,53 \\
\hline 748,08 & 447,55 & 1274,33 & 2469,96 & 0,30 & 0,18 & 0,52 \\
\hline 8862,07 & 12865,03 & 19954,37 & 41681,47 & 0,21 & 0,31 & 0,48 \\
\hline
\end{tabular}


Pada penelitian ini pada iterasi ke-1 nilai $P_{1}-P_{1-1}$ masih lebih besar dari 0,1 yang dibuktikan pada tabel 5 .

Tabel 5. Kesimpulan Iterasi-1

\begin{tabular}{lr}
\hline \multicolumn{2}{c}{ KESIMPULAN } \\
\hline$P_{1}$ & 31305,94 \\
\hline$P_{1-1}$ & 0 \\
\hline$P_{1}-P_{1-1}$ & 31305,94 \\
\hline
\end{tabular}

Pada tabel 5 nilai $P_{1}-P_{1-1}$ masih menunjjukan 31305,9 yang berarti masih lebih besar dari 0,1 . Sehingga dilakukan iterasi selanjutnya sampai mendapatkan nilai $P_{\mathrm{t}} \mathrm{P}_{\mathrm{t}-1}<0,1$. Iterasi berhenti pada Iterasi ke-3 dengan hasil kesimpulan Iterasi pada tabel 6.

Tabel 6. Kesimpulan Iterasi-3

\begin{tabular}{lr}
\hline \multicolumn{2}{c}{ KESIMPULAN } \\
\hline $\mathrm{P}_{3}$ & 73282,4002 \\
\hline $\mathrm{P}_{3-1}$ & 73601,0521 \\
\hline $\mathrm{P}_{3}-\mathrm{P}_{3-1}$ & 318,651891 \\
\hline
\end{tabular}

Dari hasil Iterasi ke-3 didapatkan nilai $P_{3}-P_{3-1}$ yaitu $-318,6519$ yang berarti nilai $P_{t}$ sudah lebih kecil dari 0,1. Dari hasil tersebut berarti proses cluster berhenti. Hasil dari derajat keanggotaan cluster pada tabel 7 berdasarkan data kategori yang ada.

Tabel 7. Derajat Keanggotaan cluster

\begin{tabular}{rrrrrr}
\hline \multirow{2}{*}{ Data Ke } & \multicolumn{2}{c}{ Derajat Keanggotaan Pada Cluster Ke- } & Cenderung & \multirow{2}{*}{ Cluster } \\
\cline { 2 - 5 } & 1 & 2 & 3 & Masuk Cluster & \\
\hline 1 & 0,471148593 & 0,326928714 & 0,201922692 & 0,471148593 & 1 \\
\hline 2 & 0,364772017 & 0,411740978 & 0,223487005 & 0,411740978 & 2 \\
\hline 3 & 0,052821547 & 0,134113188 & 0,813065266 & 0,813065266 & 3 \\
\hline 4 & 0,008807849 & 0,073783222 & 0,917408929 & 0,917408929 & 3 \\
\hline 5 & 0,184392828 & 0,25075448 & 0,564852692 & 0,564852692 & 3 \\
\hline 6 & 0,164238197 & 0,244788112 & 0,59097369 & 0,59097369 & 3 \\
\hline 7 & 0,379030624 & 0,473484628 & 0,147484748 & 0,473484628 & 2 \\
\hline 8 & 0,396525722 & 0,254407743 & 0,349066534 & 0,396525722 & 1 \\
\hline 9 & 0,474740313 & 0,132366377 & 0,39289331 & 0,474740313 & 1 \\
\hline 10 & 0,198708807 & 0,272750754 & 0,528540439 & 0,528540439 & 3 \\
\hline
\end{tabular}

Dari hasil perhitungan derajat keanggotaan pada cluster maka akan dicari nilai maksimal dari 3 cluster yaang nilainya akan di masukkan ke dalam kolom cenderung masuk cluster. Kemudian dari nilai maksimal tersebut akan dilihat nilai masuk ke dalam derajat keanggotaan cluster keberapa. Data yang masuk ke dalam cluster 1 ada 3 kategori buku, kemudian yang masuk ke cluster 2 ada 2 kategori dan yang ada dalam cluster 3 ada 5 kategori seperti yang terlihat pada tabel 8 .

Tabel 8. Cluster buku berdasarkan banyaknya peminjaman

\begin{tabular}{cccl}
\hline \multicolumn{2}{c}{ Cluster } & $\begin{array}{c}\text { Jumlah } \\
\text { Kategori }\end{array}$ & \multicolumn{1}{c}{ Nama Kategori buku } \\
\hline 1 & $\begin{array}{c}\text { Sangat } \\
\text { sering }\end{array}$ & 3 & $\begin{array}{l}\text { Sistem-Sistem, Teknik Komunikasi, } \\
\text { dan Pertanian }\end{array}$ \\
\hline 2 & Sering & 2 & Pemrograman komputer, IImu Teknik \\
\hline 3 & Jarang & 5 & $\begin{array}{l}\text { Data-data dalam sistem komputer, } \\
\text { komunikasi komputer, ensiklopedia, } \\
\text { matematika, teknologi kimia }\end{array}$ \\
\hline
\end{tabular}

90 | IJAI (Indonesian Journal of Applied Informatics) 


\section{KESIMPULAN}

Dari serangkaian ujicoba dan analisis pada perhitungan clustering peminjaman buku perpustakaan PDD-UNS menggunakan Fuzzy C-Means Clustering dpat diambil kesimpulan pada cluster 1 beranggotakan DDC dengan buku yang sangat sering dipinjam pada tahun 2013-2017, jenis buku yang yang terdapat pada cluster 1 antara lain : Sistem-sistem, Teknik komunikasi, dan Pertanian. Kemudian pada cluster 2 beranggotakan DDC dengan buku yang sering dipinjam pada tahun 2013-2017, buku yang yang terdapat pada cluster 2 antara lain : Pemrograman komputer dan IImu Teknik. Sedangkan pada cluster 3 beranggotakan DDC dengan buku yang tidak sering dipinjam pada tahun 2013-2017, jenis buku yang yang terdapat pada cluster 3 antara lain : Data-data dalam sistem komputer, komunikasi komputer, Ensiklopedia, Matematika, Teknologi kimia. Pada penelitian ini data yang digunakan untuk perhitungan hanya 10 kategori buku, untuk penelitian selanjutnya dapat menambahkan kategori yang dapat digunakan untuk parameter dalam clustering buku pada perpustakaan.

\section{DAFTAR PUSTAKA}

[1] A. S. Honggowibowo, "Sistem Pendukung Keputusan Pengadaan Bahan Pustaka Perpustakaan Stt Adisutjipto Menggunakan Metode Topsis," Conf. Senat. STT Adisutjipto Yogyakarta, vol. 2, p. 101, 2016.

[2] G. A. Pribadi, "Aplikasi Pengadaan Buku Perpustakaan Menggunakan Metode Simple Additive Weighting (Studi Kasus: Sekolah Menengah Pertama Negeri 1 Jepara)," 2014.

[3] T. A. Leah, "Perkembangan Koleksi Bahan Pustaka Melalui Pengadaan pada Tahun 2013-2015 di Perpustakaan Universitas Medan Area," 2017.

[4] C. S. Pribadi, "Sistem Pendukung Keputusan Pengadaan Buku Perpustakaan STIKOM Surabaya Menggunakan Metode Fuzzy C-Means Clustering," pp. 1-9.

[5] A. Ahmad Dony Susety01, "Sistem Rekomendasi Pengadaan Buku Pada Badan Arsip Dan Perpustakaan Daerah Provinsi Jawa Tengah Menggunakan Metode Fuzzy C-Means Clustering."

[6] A. B. Hastuti, E. Utami, and E. T. Luthfi, "Implementasi Metode Fuzzy C-Means Dan Topsis Dalam Membangun Sistem Pendukung Keputusan ( Studi Kasus: Penentuan Jurusan Di Sma Negeri 1 Wonosari )," J. Dasi, vol. 14, no. 2, pp. 9-15, 2013.

[7] Pratama AA, Suciati N, Purwitasari D. Implementasi Fuzzy C-Means untuk Pengelompokan Citra Batik Berdasarkan Motif dengan Fitur Tekstur. Jurnal Teknik Pomits. 2012;1(1):1-4.

[8] Bifawaidati I. Penerapan Algoritma Fuzzy C-Means Untuk Klasifikasi Citra Tenun Berdasarkan Fitur Tekstur (Doctoral dissertation, Institut Teknologi Sepuluh Nopember).

[9] Masudia PE, Arinie F, Mustafa LD. Clustering Data Remunerasi Dosen Untuk Penilaian Kinerja Menggunakan Fuzzy c-Means. Jurnal RESTI (Rekayasa Sistem dan Teknologi Informasi). 2018 Apr 16;2(1):288-94.

[10] Ulfah AN. Analisis Kinerja Algoritma Fuzzy C-Means dan K-Means pada Data Kemiskinan. JATISI (Jurnal Teknik Informatika dan Sistem Informasi). 2015 Mar 12;1(2):139-48.

[11] Rusdiana L. Aplikasi Berbasis Fuzzy C-Means Dalam Penentuan Predikat Kelulusan Mahasiswa. Jurnal IImiah IImu Komputer Fakultas IImu Komputer Universitas AI Asyariah Mandar. 2016 Sep 1;2(2):1-9.

[12] Suci W. Implementasi Fuzzy C-Means Sebagai Pendukung Keputusan Sistem Kelayakan Mustahik Pada Dompet Dhuafa Yogyakarta.

[13] Puspita SR, Nhita F. Implementasi Algoritma Fuzzy C-means Untuk Mengkategorikan Tingkat Penjualan Produk Pada Data Transaksi Swalayan. eProceedings of Engineering. 2018 Dec 1;5(3).

[14] Islami AK, Widodo E. Pengelompokkan Kepemilikan Jaminan Kesehatan Menggunakan Fuzzy C-Means Algorithm (Studi Kasus: Kabupaten/Kota di Provinsi Jawa Tengah Tahun 2015). InProsiding SI MaNIS (Seminar Nasional Integrasi Matematika dan Nilai-Nilai Islami) 2017 Jul 31 (Vol. 1, No. 1, pp. 299-305).

[15] Sutoyo MN, Sumpala AT. Penerapan Fuzzy C-Means untuk Deteksi Dini Kemampuan Penalaran Matematis. Scientific Journal of Informatics. 2015;2(2):129-35. 